\title{
Musim pemijahan dan ukuran layak tangkap udang jerbung (Penaeus merguiensis) di perairan Dumai dan sekitarnya, Riau
}

\author{
Andina Ramadhani Putri Pane*, Ali Suman \\ Balai Riset Perikanan Laut (KKP), Cibinong - Bogor, Jawa Barat \\ *Koresponden E-mail: paneandina@gmail.com
}

(Diterima 21 Februari 2020|Disetujui 8 Juni 2020|Diterbitkan 30 Juli 2020)

\begin{abstract}
The high demand for shrimp commodities will increase catching to spur production so that it will affect the shrimp population. This scientific study will discuss the spawning season of banana shrimp (Penaeus merguiensis), catch size, and environmental conditions of Dumai and surrounding waters. This research was conducted from April to December 2018 using survey methods around the waters of Dumai, Riau. Data collection was carried out monthly on 4,677 banana shrimps assisted by enumerators. The analysis was carried out on the relationship between carapace length and body weight, sex ratio, gonad maturity level, and catch size. The condition of the aquatic environment that influences the process of reproduction becomes a comparison in determining management efforts. Banana shrimp size structure $18-60 \mathrm{~mm}$, dominant at $28 \mathrm{~mm}$ and negative allometric growth patterns. The genital ratio shows that female shrimp are more dominant than males and the spawning season lasts throughout the year with peaks in June and December. The length at first capture was $34.5 \mathrm{~mm}$ with the length at first maturity was $30.8 \mathrm{~mm}$ (Lc> Lm), meaning that it had spawned before being capture. However, the polluted water environment can interfere with the process of growth and population growth even though various environmental parameters are still within normal limits. So the thing to do is to close the shrimp catching area in June and December, not catch in the spawning area, the size of the shrimp that can be caught is $31 \mathrm{~mm}$ and protect the aquatic environment from pollution.
\end{abstract}

\section{Keywords: spawning season, catch size, banana prawn, Dumai, FMA 571}

Perikanan di Riau sangat potensial karena memberikan banyak kontribusi dalam menyumbang produk perikanan. Sumberdaya perikanan yang banyak di perairan ini berbagai jenis baik pelagis besar, pelagis kecil, udang dan krustasea dan demersal di beberapa lokasi. Namun, penangkapan ikan di Selat Malaka sudah menunjukkan exploitation rate relatif tinggi dan over fishing (Priatna \& Wijopriono, 2011 ; Purnomo, 2012).

Produksi perikanan di Propinsi Riau yang berasal dari perikanan laut meningkat dari tahun 2006 sebesar 99.194 Ton menjadi 102.101 Ton (2016) dan menjadi 119.274 Ton (2018). Dumai sebagai kota pelabuhan menjadi salah satu sentra perikanan karena letaknya yang berada di tepi Pantai Timur Sumatera. Produksi perikanan di Kota Dumai 95 \% berasal dari laut dengan rata-rata produksi tahun 2001 - 2008 adalah 1.725,29 Ton/ Tahun (Sari et al, 2010). Namun dari jumlah tersebut, produksi udang hanya sekitar 8,9 $\%$ dari total produksi tersebut (BPS, 2019). Sumberdaya perikanan di wilayah ini yang menjadi unggulan adalah ikan kurau, malung, senangin, bawal putih, udang putih, udang mantis dan ikan tenggiri (Sari et al, 2009).

Produksi udang yang ditangkap di laut pada tahun 2018 adalah 4.436.996,76 Ton (BPS Riau, 2019) dan yang tertinggi berasal dari Kabupaten Bengkalis sebesar 1.293.685,25 Ton, sedangkan Dumai sebesar $608.190,06$ Ton. Jumlah tersebut menunjukkan bahwa penangkapan udang dilakukan secara intensif untuk memenuhi permintaan.

Peningkatan produksi harus dibarengi dengan kelestarian sumberdaya ikan serta lingkungan habitat hidup yang baik agar populasinya terjaga.
Penangkapan ikan serta tekanan lingkungan meningkatkan dampak kerusakan populasi sumberdaya ikan. Kerusakan lingkungan dan kegiatan eksploitasi yang berlebihan menjadi ancaman bagi kelestarian sumberdaya ikan (Purwaningsih et al., 2012). Menurut Siregar, Edward (2010) \& Syahrial (2018) bahwa perairan Dumai dan sekitarnya telah mengalami pencemaran karena aktivitas kegiatan industri kilang minyak bumi, kilang kelapa sawit, doking kapal, akitivitas pelabuhan serta pelayaran di Selat Malaka. Ditambahkan oleh Hamonangan \& Hartono (2010) bahwa struktur plankton diperairan pesisir Dumai sudah menunjukkan kondisi tercemar. Bahkan muara sungai yang berada di sekitar Kota Dumai juga sudah tercemar karena konsentrasi amonia, nitrat dan nitrit diatas baku mutu yang dietatapkan (Merian et al, 2016). Kondisi lingkungan yang mengalami kerusakan tentu menimbulkan permasalahan karena sumberdaya ikan dapat mengganggu siklus daur hidup dengan normal.

Peningkatan jumlah eksploitasi dan tekanan lingkungan perairan yang mengalami kerusakan dapat mengancam kelestarian udang di perairan Dumai. Tujuan dari tulisan ini adalah membahas musim pemijahan udang dan ukuran udang layak tangkap serta lingkungan perairan yang mempengaruhi siklus hidup udang. Diharapkan tulisan ini dapat menjadi salah satu sumber informasi ilmiah dalam pengelolaan perikanan di Propinsi Riau khususnya perikanan udang di perairan Dumai dan sekitarnya 


\section{BAHAN DAN METODE}

Penelitian ini dilakukan di perairan Dumai dan sekitarnya selama 8 bulan yaitu dari April sampai dengan Desember 2018 dengan metode survey serta pengumpulan data bulanan dibantu oleh tenaga enumerator. Penelitian dilakukan dengan pengamatan dan pengukuran sampel udang di sentra pengumpulan udang yang berasal dari Perairan Dumai dan Bengkalis (Gambar 1). Pengamatan aspek biologi dilakukan pada 4.677 ekor udang Penaeus merguiensis baik jantan maupun betina. Pengamatan meliputi panjang karapas, bobot tubuh udang dan tingkat kematangan gonad udang.

\section{Gambar 1. Peta Lokasi}

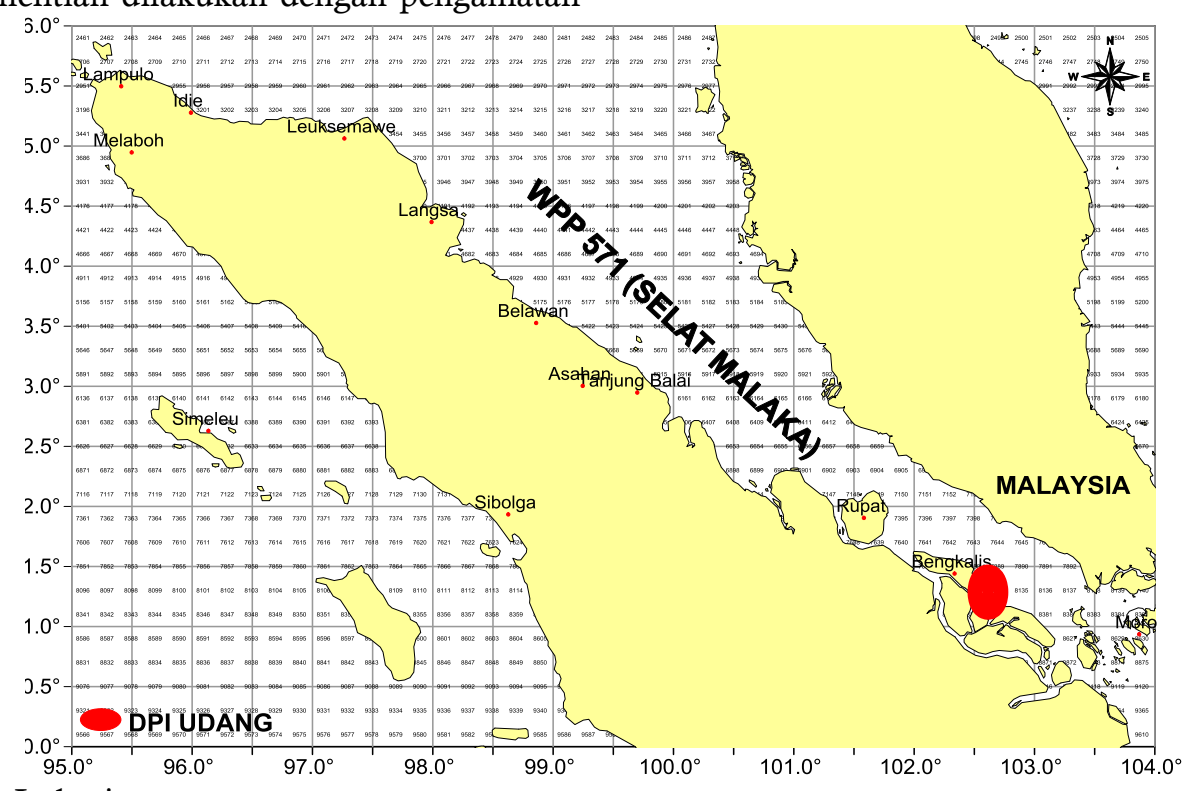

Parameter lingkungan perairan di Dumai dan sekitarnya diperoleh dengan metode literatur dan dihubungkan dengan aktivitas biologi udang jerbung. Sifat pertumbuhan udang diperoleh dari hubungan panjang karapas dengan bobot tubuh udang mengikuti persamaaan (Ball \& Rao, 1984) :

\author{
$\mathrm{W}=\mathrm{a} \mathrm{Lb}$ \\ dimana \\ W : bobot tubuh udang (gram); \\ $\mathrm{L}$ : panjang karapas udang $(\mathrm{mm})$; \\ a : konstanta; \\ $\mathrm{b}$ : nilai eksponensial
}

Nisbah kelamin udang dihitung dengan membandingkan antara jumlah udang jantan dengan udang betina dan diuji dengan uji chi square (Steel \& Torrie, 1980).

Tingkat kematangan gonad udang betina ditentukan dengan Motoh (1981) yang membagi menjadi 5 fase yaitu belum matang (ovari yang masih setipis benang dan bening), kematangan awal (ovari yang semakin berkembang dan mulai tampak), kematangan lanjutan (ovari mulai berwarna hijau dan mulai mengisi rongga kepala dan berkembang sampai ke bawah bagian ekor memanjang), kematangan telur sempurna (ovari berwarna hijau tua dan memenuhi rongga kepala dan sempurna terlihat memanjang sampai dengan ekor) dan terakhir spent (bagian punggung tubuh sudah melunak dan ovari sudah dilepaskan)
Selanjutnya data ukuran udang ditabulasi secara bulanan untuk dilakukan analisis ukuran udang pertama kali tertangkap (length at first capture, CLc). Selanjutnya dibuat grafik hubungan antara distribusi kelas lebar karapas (sumbu $\mathrm{x}$ ) dengan persentase kumulatif jumlah kepiting (sumbu y), sehingga terbentuk kurva berbentuk S (sigmoid). Nilai CLc dinyatakan sebagai titik potong antara kurva $50 \%$ frekuensi kumulatif dengan nilai lebar karapas (Saputra, 2009). Ukuran pertama kali matang gonad (Lm) diperoleh berdasarkan fungsi logistik dengan memasukkan PLm dan panjang karapas dengan persamaan sebagai berikut (King, 1995) :

$$
\text { P_CLm }=1 /(1+\exp (\mathrm{aCl}+\mathrm{b}))
$$

\section{HASIL}

\section{Struktur Ukuran dan Hubungan Panjang Karapas dengan Bobot Tubuh}

Udang Penaeus merguiensis yang ditemukan selama penelitian di wilayah ini berukuran 18-60 $\mathrm{mm}$ dengan puncak berbeda setiap bulan. Struktur ukuran tertinggi pada bulan Agustus dan Desember (Tabel 1). Udang jantan dan betina relatif ditemukan pada ukuran yang sama dengan ukuran dominan pada selang kelas $28 \mathrm{~mm}$ (Gambar 2). Udang jantan ditemukan pada ukuran $50 \mathrm{~mm}$, sedangkan udang betina ditemukan pada ukuran lebih besar daripada jantan. 
Tabel 1. Struktur Ukuran Udang Jerbung secara Bulanan

\begin{tabular}{lcc}
\hline Bulan & Kisaran $(\mathrm{mm})$ & Dominan $(\mathrm{mm})$ \\
\hline Apr & $18-38$ & 26 \\
May & $25-50$ & 28 \\
Jun & $22-50$ & $32-34$ \\
Jul & $26-34$ & 28 \\
Aug & $22-60$ & 34 \\
Sep & $26-50$ & 28 \\
Oct & $26-50$ & 28 \\
Nop & $26-50$ & 28 \\
Des & $22-50$ & 34 \\
Total & $18-60$ & 28
\end{tabular}

Gambar 2. Struktur Ukuran Udang Jerbung di Dumai dan Sekitarnya

Hubungan panjang karapas dengan bobot tubuh udang di perairan ini mempunyai persamaan $\mathrm{W}=0,0123 \mathrm{~L} 2,2105$ dengan nilai $\mathrm{b}=2,2105$. Nilai ini menunjukkan hubungan allometrik negatif yang artinya pertambahan panjang tubuh lebih cepat dari pertambahan bobot tubuh udang (Gambar 3).
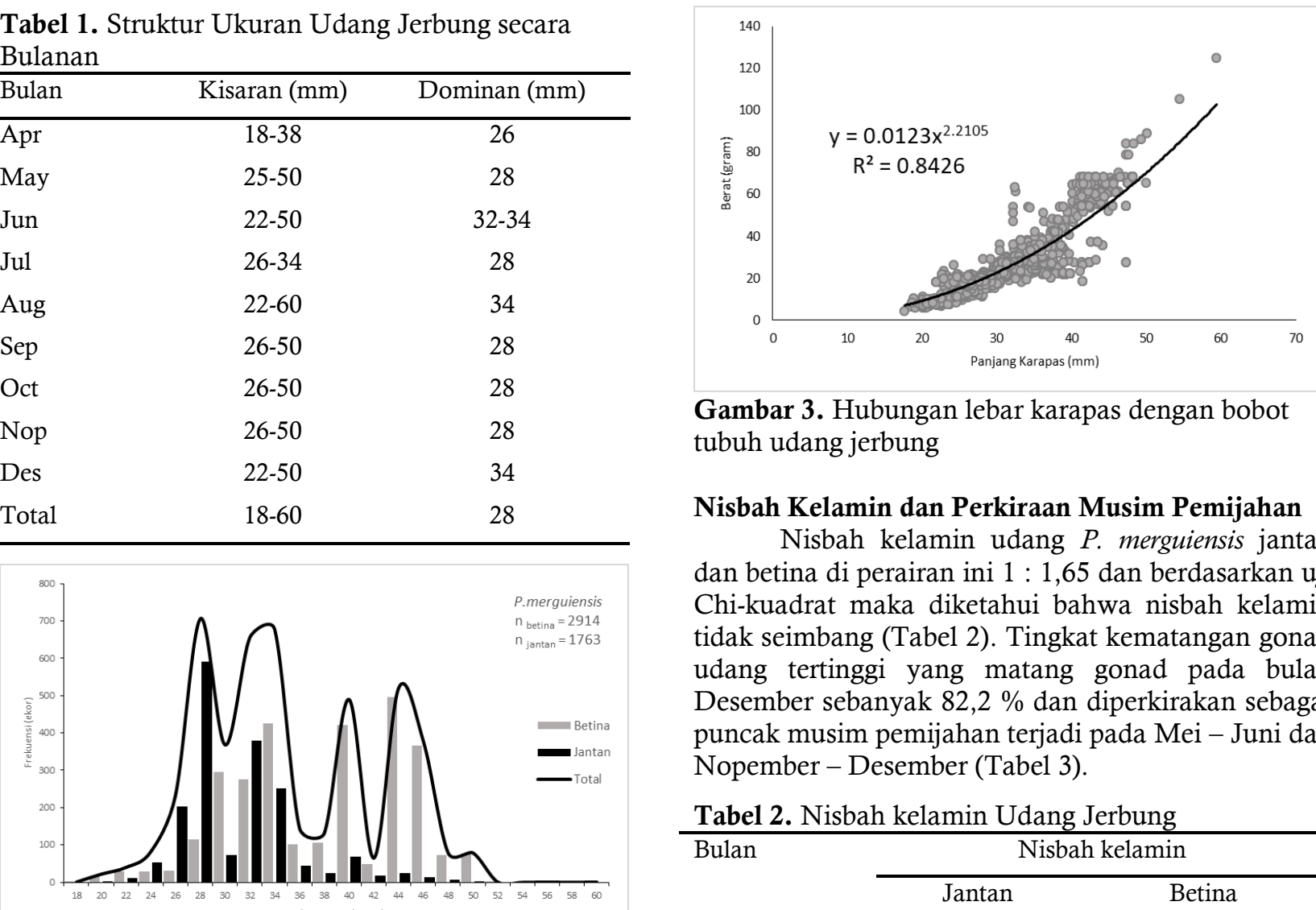

Gambar 3. Hubungan lebar karapas dengan bobot tubuh udang jerbung

\section{Nisbah Kelamin dan Perkiraan Musim Pemijahan}

Nisbah kelamin udang $P$. merguiensis jantan dan betina di perairan ini $1: 1,65$ dan berdasarkan uji Chi-kuadrat maka diketahui bahwa nisbah kelamin tidak seimbang (Tabel 2). Tingkat kematangan gonad udang tertinggi yang matang gonad pada bulan Desember sebanyak 82,2 \% dan diperkirakan sebagai puncak musim pemijahan terjadi pada Mei - Juni dan Nopember - Desember (Tabel 3).

Tabel 2. Nisbah kelamin Udang Jerbung

\begin{tabular}{lcc}
\hline Bulan & \multicolumn{2}{c}{ Nisbah kelamin } \\
\cline { 2 - 3 } Apr & Jantan & Betina \\
Mei & 1 & 1.8 \\
Jun & 1 & 1.73 \\
Jul & 1 & 2.06 \\
Agust & 1 & 1.65 \\
Sept & 1 & 1.31 \\
Okt & 1 & 1.69 \\
Nop & 1 & 1.67 \\
Des & 1 & 1.73 \\
Total & 1 & 1.87 \\
\hline
\end{tabular}

Tabel 3. Tingkat Kematangan Gonad Udang Jerbung

\begin{tabular}{lcccccc}
\hline Bulan & \multicolumn{3}{c}{ Tingkat Kematangan Gonad } & \multicolumn{2}{c}{ Persentase } \\
\cline { 2 - 4 } & TKG 1 & TKG 2 & TKG 3 & TKG 4 & Immature & Mature \\
Apr & 206 & 2 & 1 & 0 & 99.5 & 0.5 \\
May & 106 & 43 & 13 & 218 & 39.2 & 60.8 \\
Jun & 25 & 23 & 56 & 98 & 23.8 & 76.2 \\
Jul & 93 & 47 & 30 & 209 & 36.9 & 63.1 \\
Aug & 121 & 58 & 23 & 264 & 38.4 & 61.6 \\
Sept & 91 & 40 & 12 & 209 & 37.2 & 62.8 \\
Okt & 89 & 46 & 30 & 210 & 36.0 & 64.0 \\
Nop & 105 & 42 & 13 & 220 & 38.7 & 61.3 \\
Des & 17 & 14 & 56 & 87 & 17.8 & 82.2 \\
Total & 836 & 301 & 178 & 1428 & 41.5 & 58.5 \\
\hline
\end{tabular}


Ukuran pertama kali tertangkap (Lc) dan ukuran pertama kali matang gonad $(\mathrm{Lm})$

Berdasarkan hasil analisis diperoleh nilai Lc udang jerbung di perairan Dumai adalah $34,1 \mathrm{~mm}$ (Gambar 4a) dengan nilai Lm-nya sebagai $30,8 \mathrm{~mm}$
(Gambar 4b). Berdasarkan hasil tersebut diketahui bahwa nilai Lc lebih besar daripada nilai Lm dan hal ini menunjukkan bahwa udang yang tertangkap telah melakukan pemijahan. Namun masih ada sekitar 11\% udang betina yang belum matang gonad tertangkap.
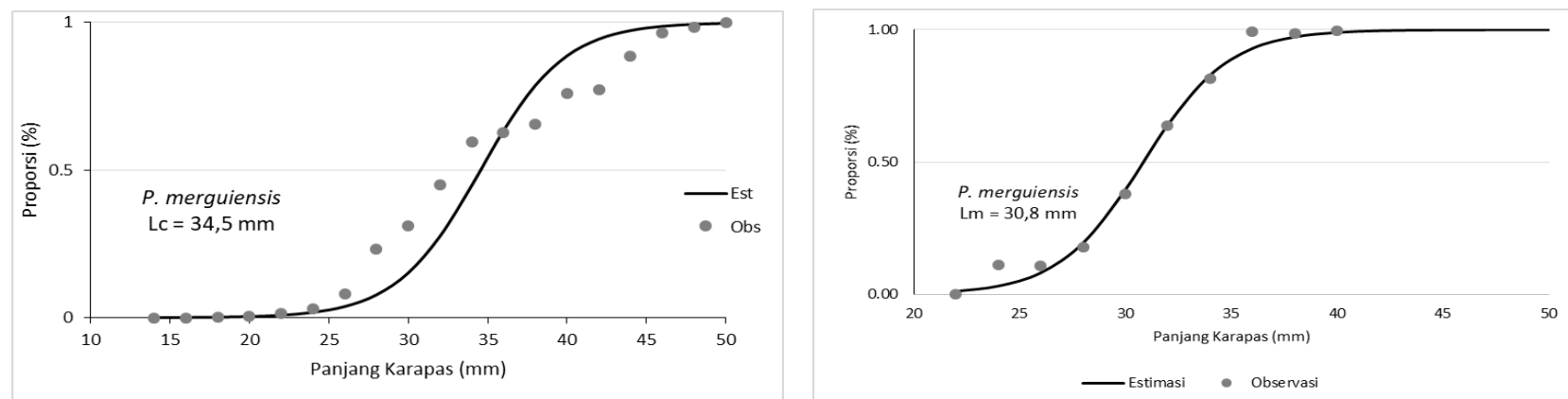

Gambar 4. Ukuran pertama kali tertangkap (Lc) dan Ukuran pertama kali matang gonad (Lm) udang jerbung

\section{PEMBAHASAN}

Struktur ukuran udang Penaeus merguiensis di perairan Dumai dan sekitarnya cenderung berukuran lebih besar daripada yang ditemukan diperairan lainnya (Tabel 4). Perbedaan ukuran udang dipengaruhi oleh lingkungan dan ketersediaan makanan serta lokasi penangkapan udang tersebut. Ketersediaan makanan di suatu lokasi seperti moluska, krustasea, detritus menjadi daya tarik bagi udang untuk berkumpul sehingga udang yang tertangkap berbeda ukurannya sesuai dengan lingkungannya (Sentosa et al, 2017). Hal tersebut didukung oleh pernyataan Ariani (2016) bahwa perairan ini kaya nutrient yang berasal dari lautan dan daratan yang menyebabkan perairan ini subur atas keanakeragamaan hayati.

Table 4. Struktur ukuran udang jerbung (Penaeus merguiensis) di berbagai perairan

\begin{tabular}{lll}
\hline Lokasi & Struktur Ukuran $(\mathrm{mm})$ & Sumber \\
\hline Tarakan & $26,03-43,36$ & Kembaren et al, 2013 \\
Sampit & $18-58$ & Nurdin \& Kembaren, 2015 \\
Utara Jawa Tengah & Jantan : 28,28 $\pm 0,49$ Betina : 27,57 $\pm 0,55$ & Tirtadanu \& Ernawati, 2017 \\
Bengkalis, Riau & $12-26$ & Pane \& Hasanah, 2017 \\
Kaimana, Papua Barat & $25-49$ & Tirtadanu \& Panggabean, 2018 \\
Cilacap & $11-42$ & Wagiyo et al, 2018 \\
Dumai, Riau & $18-60$ & Penelitian ini \\
\hline
\end{tabular}

Selain itu, perbedaan salinitas antara lepas pantai dan daerah pantai juga menyebabkan perbedaan ukuran panjang ikan (Mallawa, 2012). Andrianto dalam Amri et al (2018) menyatakan bahwa salinitas perairan mempengaruhi proses biologi seperti jumlah makanan yang dikonsumsi, laju pertumbuhan, nilai konversi makanan serta daya kelangsungan hidup. Salinitas di perairan ini adalah 29,40-31,40 psu atau 24-30 psu dengan rata-rata 27,7 psu serta 28-32 psu yang menunjukkan kesuburan perairan di Dumai masih tinggi (Milero \& Sohn dalam Efrizal, 2006 ; Purba \& Khan, 2010 ; Syahminan et al, 2015 ; Marlian, 2017 ; Nufus, 2018). Hal ini sejalan dengan penelitian Silaen \& Mulya (2018) pada salinitas 27 psu kepadatan udang ini tertinggi di perairan Kampung Nipah, Perbaungan Sumatera Utara. Menurut Nye et al (2018) fitoplankton juga berkembang baik ada salinitas 15-30 psu dan untuk perkembangan udang jerbung adalah 25-35 psu (Nur et al, 2018). Oleh karena hal tersebut maka kadar salinitas di perairan Dumai masih mendukung untuk pertumbuhan udang.

Hubungan panjang karapas dengan $b=2,2105$ yang bersifat allometrik negatif, yang sejalan dengan hasil penelitian di perairan yang sama pada tahun
(Pane \& Kembaren, 2015 ; Pane \& Hasanah, 2017 ; Pane \& Widiyastuti, 2017), diperairan Cilacap (Saputra et al, 2013) \& (Wagiyo et al, 2018). Sifat pertumbuhan dipengaruhi oleh banyak faktor baik makanan dan suhu perairan (Monterio dalam Fauzi et al., 2013). Makanan yang tidak mencukupi menyebabkan bobot tubuh udang bertambah lebih lambat dibandingkan dengan pertambahan panjang karapasnya dan pencemaran yang terjadi diperairan ini karena aktivitas perminyakan dapat menjadi salah satu penyebab. Hal tersebut karena menurunnya proses fotosintensis sehingga mengurangi jumlah plankton dan mengurangi oksigen terlarut di perairan (Nufus, 2018). Padahal jumlah fitoplankton merupakan hal penting dalam rantai makanan tropic level karena menjadi sumber makanan bagi organisme lainnya (Marlian, 2017). Proses fotosintesis ini juga dipengaruhi oleh $\mathrm{PH}$ air karena ikut menentukan produktivitas primer perairan (Ariani, 2016). PH Dumai 8-8,5 (Purba \& Khan, 2010), 7,8 (Siregar \& Edward, 2010) dan 6-8 (Ariani, 2016) dan memenuhi untuk $\mathrm{PH}$ yang baik bagi pertumbuhan udang jerbung adalah 7,9-8,7 (Nur et al, 2018). 
Nisbah kelamin udang yang tidak seimbang karena didominasi oleh udang betina menunjukan bahwa perairan tersebut masih baik karena udang betina dapat membantu agar penambahan individu dapat berlangsung. Hasil penelitian yang sama juga ditemukan di perairan Cilacap (Tirtadanu \& Chodrijah, 2020), di perairan Perbaungan (Silaen \& Mulya, 2018) dan di Kupang (Marini et al, 2017).

Darmono dalam Saputra et al (2013) menyatakan bahwa udang $P$. merguiensis jantan ratarata memiliki umur yang pendek, sehingga dapat menjadi salah satu penyebab semakin lama udang betina jumlahnya lebih banyak daripada udang jantan. Ketidakseimbangan nisbah kelamin dapat menyebabkan penurunan potensi pemijahan. Bahkan dinyatakan oleh Courtney et al dalam Tirtadanu \& Ernawati (2016) bahwa ketidakseimbangan kelamin pada spesies Penaeid merupakan hal yang tidak biasa.

Musim pemijahan di perairan ini terjadinya sepanjang tahun dengan puncaknya diprediksi yaitu pada bulan Juni dan Desember. Ini berbeda dengan di perairan Laut Arafura sekitar perairan Dolak yang terjadi pada Januari - April dan September Desember (Hargiyatno et al, 2015), di Tanah Laut pada November (Suman, 2017) dan di Bengkalis pada bulan April (Suman et al, 2020). Sedangkan menurut Kusrini (2011) puncak pemijahan udang ini adalah pada bulan Maret dan Desember. Perkiraan puncak musim pemijahan digunakan untuk upaya penutupan area dan musim penangkapan agar memberikan kesempatan bagi induk udang untuk melakukan pemijahan (Suman \& Prisantoso, 2017 ; Suman et al, 2020). Maka hasil dari kajian ini dapat diusulkan penutupan area penangkapan udang terutama daerah pemijahan pada bulan Juni dan Desember.
Musim pemijahan dipengaruhi oleh jumlah oksigen terlarut (DO) di perairan karena organisme memerlukannya dalam proses respirasi dan proses metabolisme pertumbuhan tubuh dan perkembangbiakan (Amri et al, 2018). Menurut Nufus (2018) jumlah oksigen terlarut di perairan ini adalah oksigen terlarut 5,10-7,20 ppm, 3,2-6,5 ppm (Purba \& Khan, 2010) dan ini baik untuk organisme karena $>5$ ppm (Efrizal, 2006). Suhu juga memberikan pengaruh pada proses fotosintesis di perairan dan proses metabolisme serta siklus reproduksi (Abdurahman \& Soejono dalam Ariani, 2016). Suhu perairan di Dumai adalah sekitar 25-320C (Purba \& Khan, 2010 ), 30,40C (Siregar \& Edward, 2010), 28,30-30,700C (Syahrial et al, 2017), 28-320C (Ariani, 2016) sedangkan suhu yang baik untuk kehidupan udang adalah 28,5-33,20C (Nur et al, 2018). Maka oksigen terlarut dan suhu di perairan Dumai masih mendukung untuk proses reprduksi dan metabolisme udang.

Ukuran udang yang pertama kali tertangkap $(\mathrm{Lc})=34,1 \mathrm{~mm}$ dan ukuran udang pertama kali matang gonad $(\mathrm{Lm})=30,8 \mathrm{~mm}$ menunjukkan bahwa udang telah melakukan pemijahan dahulu baru tertangkap ( $\mathrm{Lc}>\mathrm{Lm}$ ). Namun, hasil penelitian di perairan lainnya termasuk di perairan Selat Malaka adalah udang lebih dahulu mengalami penangkapan sebelum melakukan pemijahan (Tabel 5). Artinya udang belum melakukan penambahan individu baru telah tertangkap sehingga apalagi terjadi terus menerus akan menyebabkan penurunan poulasi. Maka berdasarkan hal tersebut kondisi populasi udang di perairan Dumai dan sekitarnya masih terjaga. Perbedaan ukuran udang pertama kali matang gonad dipengaruhi spesies, umur, suhu dan lingkungan. Namun menurut Sumiono dalam Suman et al (2017) umumnya memijah pada ukuran $30 \mathrm{~mm}$.

Tabel 5. Ukuran Pertama Kali Tertangkap (Lc) dan Pertama Kali Matang Gonad (Lm) di berbagai perairan

\begin{tabular}{llll}
\hline Perairan (waters) & Lc $(\mathrm{mm})$ & Lm $(\mathrm{mm})$ & Sumber (source) \\
\hline Merauke, Papua & & 60,26 & Melmambessy, 2011 \\
Sampit, Kalimantan Tengah & 30,05 & 39,4 & Nurdin \& Kembaren, 2015 \\
Teluk Cendrawasih, Papua & & 32,2 & Kembaren \& Ernawati, 2015 \\
Arafua & 28.78 & 38.7 & Hargiyatno et al, 2013 \\
Tarakan, Timur Borneo & 35 & 33,86 & Kembaren \& Suman, 2013 \\
Langsa, NAD & 31,6 & 34,8 & Pane \& Kembaren, 2015 \\
Utara Jawa Tengah & 29,40 & 42,85 & Tirtadanu \& Ernawati, 2016 \\
Tanah Laut, Kalimantan Selatan & & 43,39 & Suman et al, 2017 \\
Cilacap, Jawa Tengah & & 38,3 & Suman \& Prisantoso, 2017 \\
Aceh Timur, NAD & 28,2 & 28,3 & Pane \& Widiyastuti, 2017 \\
Bengkalis, Riau & 29,3 & 31,9 & Pane \& Hasanah, 2017 \\
Cilacap & 17.147 & & Wagiyo et al, 2018 \\
Dumai, Riau & 34,1 & 30,8 & Penelitian ini \\
\hline
\end{tabular}


Maka dapat diketahui bahwa udang yang belum matang gonad masih tertangkap sekitar $11 \%$ yang menunjukkan bahwa penangkapan udang sudah dominan yang matang gonad. Udang yang telah matang gonad telah tertangkap sebanyak $89 \%$ menjadi indikasi bahwa proses penambahan individu baru di perairan ini masih belum mengalami tekanan dan ini selaras dengan penelitian Suman \& Prisantoso (2017) di Cilacap. Lingkungan perairan Dumai secara umum untuk parameter suhu air, $\mathrm{pH}$ air, kecepatan arus, kecerahan, salinitas perairan Laut Dumai berada dalam kondisi baik dan konsentrasi logam berat $\mathrm{Pb}$ dan $\mathrm{Cd}$ pada sedimen lingkungan masih layak untuk kehidupan organisme perairan serta memiliki status pencemaran berada dibawah standar baku mutu yang ditetapkan oleh beberapa negara (Syahminan et al, 2015).

Pencemaran lingkungan yang terjadi di perairan Dumai dan sekitarnya akibat aktivitas perminyakan, lalu lintas kapal, kilang kapal sawit dan industri lainnya tidak mempengaruhi secara langsung ke siklus hidup udang. Nelayan penangkap udang cenderung melakukan penangkapan jauh dari lokasi industri dan perminyakan tersebut sehingga udang tidak terdampak langsung dan masih dapat melakukan aktivitas biologisnya.

Namun, pemanfatan perikanan udang di perairan Selat Malaka secara umum sudah melewati batasan berdasarkan keputusan Menteri Kelautan dan Perikanan Nomor 50 Tahun 2017 yaitu sebesar E = 1,59 yang sudah melewati jumlah tangkapan yang diperbolehkan sebanyak $59 \%$. Berdasarkan kajian udang di perairan Bengkalis dan sekitarnya hanya mengalami $8 \%$ spawning potential ratio (SPR) yang artinya sudah mulai mengalami overfishing (Suman et al, 2020). Maka diharapkan pengelolaan perikanan udang di Dumai dapat menjadikan musim pemijahan dan ukuran udang layak tangkap sebagai dasar dalam penetapan kebijakan. Langkah pengelolaan yang dapat diambil antara lain memberikan batasan ukuran mata jaring yang digunakan untuk menangkap udang dengan ukuran minimal $31 \mathrm{~mm}$ dan menutup perairan tempat pemijahan pada bulan Juni dan Desember. Namun kebijakan dalam hal pengelolaan perikanan juga harus diikuti dengan menjaga lingkungan perairan sekitar. Kebijakan harus diterapkan pada masyarakat serta industri agar pencemaran lingkungan perairan tidak semakin meluas dan merusak populasi udang jerbung di perairan Selat Malaka secara umum, khususnya perairan Dumai dan sekitarnya.

\section{SIMPULAN}

Puncak musim pemijahan udang jerbung (Penaeus merguiensis) terjadi pada bulan Juni dan Desember. Ukuran udang layak tangkap di perairan ini adalah $31 \mathrm{~mm}$ yang telah melewati masa pemijahan. Perairan Dumai yang sudah mengalami pencemaran dapat menjadi ancaman bagi keberlangsungan hidup sumberdaya udang. Upaya pengelolaan yang dapat dilakukan adalah menutup area (closed area) pemijahan udang pada bulan bulan Juni dan Desember, menetapkan ukuran layak tangkap udang $31 \mathrm{~mm}$ serta melakukan pembersihan perairan terutama di daerah pemijahan udang. Hal tersebut dalam membantu udang tetap mempertahankan populasinya dilingkungan perairan Selat Malaka khususnya sekitar Dumai dan Bengkalis.

\section{UCAPAN TERIMA KASIH}

Tulisan ini merupakan kontribusi dari kegiatan Penelitian Karakteristik Biologi Perikanan, Habitat Sumberdaya, dan Potensi Produksi Sumberdaya Ikan di WPP 571 Selat Malaka Tahun Anggaran 2018 pada Balai Penelitian Perikanan Laut, Jakarta. Penulis mengucapkan terima kasih kepada Mahiswara, M.Si sebagai Penanggungjawab kegiatan penelitian WPP 571 Tahun 2018. Penulis pertama merupakan kontributor utama dalam tulisan ini sedangkan penulis kedua adalah kontributor anggota

\section{DAFTAR PUSTAKA}

Amri, K., Muchlizar \& Ma'mun, A., (2018). Variasi bulanan salinitas, $\mathrm{PH}$ dan oksigen terlarut di perairan Estuari Bengkalis. Majalah Ilmiah Globe Vol 20 No. 2:57-66.DOI

http://dx.doi.org/10.24895/MIG.2018.20-2.645

Ariani F., (2016). Strategi Pengelolaan Pencemaran di Pesisir Perairan Kota Dumai. Tesis Institut Pertanian Bogor. Bogor.

Badan Pusat Statistik. (2019). Data Produksi Perikanan Tahunan 1999 - 2016. Web https://www.bps.go.id/statictable/2014/01/16/17 $11 /$ produksi-perikanan-menurut-subsektor-ribu-ton1999-2016.html. diakses pada 20 Agustus 2019 pukul 08.33 Wib.

Badan Pusat Statistik Riau. (2019). Produksi Perikanan Tangkap Menurut Propinsi dan Jenis Penangkapan 2006 - 2016. Web

https://www.bps.go.id/statictable/2009/10/05/17 05/produksi-perikanan-tangkap-menurut-provinsidan-jenis-penangkapan-2000-2016.html. diakses pada 20 Agustus 2019 pukul 08.37 Wib.

Ball, D.V. \&, and Rao, K.V. (1984). "Marine Fisheries." New Delhi : Tata Mc. Graw-Hill Publishing Company Limited., 5-24 pp.

Efrizal, T., (2006). Hubungan Beberapa Parameter Kualitas Air dengan Kelimpahan Fitoplankton di Perairan Pulau Penyengat Kota Tanjung Pinang Provinsi Kepulauan Riau. http://riset.umrah.ac.id/?p=143 diakses pada 27 Januari 2020

Fauzi, M., Prasetyo, A. P., Hargiyatno, T. I., Satria, F., \& Utama, A. A., (2013). Hubungan panjangberat dan faktor kondisi lobster batu (Panulirus penicillatus) di perairan Selatan Gunung Kidul dan Pacitan. Bawal Vol 5 No. 2: 97-102. DOI http://dx.doi.org/10.15578/bawal.5.2.2013.97-102

Hamonangan, M.E \& Hartono., (2010). Pencemaran Minyak dan Lemak di Kawasan Kepesisiran Dumai, Riau. Tesis, Ilmu Lingkungan. Universitas Gadjah Mada. Yogyakarta. 
Hargiyatno, I. T., B. Sumiono \&, Suharyanto. (2013). Laju tangkap, kepadatan stok dan beberapa aspek biologi udang jerbung (Penaeus merguiensis) di perairan Dolak, Laut Arafura. Bawal. Vol 5 No. 2: 123-129.

http://dx.doi.org/10.15578/bawal.5.2.2013.123129

Hargiyatno, I, T., Fijianggawangsa, R., \& Sumiono, B. (2015). Sebaran Spasio - Temporal Ukuran dan Densitas Udang Jerbung (Penaeus merguiensis de Man, 1907) di Sub Area Dolak, Laut Arafura (WPP - NRI 718). Jurnal Penelitian Perikanan Indonesia. 21 No. 4 Tahun 2015: 261-269. DOI http://dx.doi.org/10.15578/jppi.21.4.2015.261-269

Wagiyo, K., Damora, A \& Pane, A. R.P. (2018). Aspek Biologi, Dinamika Populasi dan Kepadatan Udang Jerbung (Penaeus merguiensis de Man, 1888) di Habitat Asuhan Estuaria Segara Anakan, Cilacap. Jurnal Penelitian Perikanan Indonesia. Vol 24 No 2 Tahun 2018: 127-136. DOI http://dx.doi.org/10.15578/jppi.24.2.2018.127-136

Kembaren, D.D., Suprapto \& Wedjatmiko. (2013). Komposisi Jenis dan Sebaran Laju Tangkap Udang Penaeid di Perairan Tarakan, Kalimantan. Status Pemanfaatan Sumberdaya Ikan di Perairan Laut Sulawesi. Bunga Rampai. Kementerian Kelautan Dan Perikanan. 153-164.

Kembaren, D.D., \& Suman, A. (2013). Biology and Population Dynamics of Banana Shrimp (Penaeus merguiensis) in Tarakan waters, Eats Borneo. Indonesian Fishries Research Journal. Vol 19 No. 2 Tahun 2013; 99-105. DOI http://dx.doi.org/10.15578/ifrj.19.2.2013.99-105

Kembaren, D, D., \& Ernawati, T. (2015). Dinamika Populasi dan Estimasi Rasio Potensi Pemijahan Udang Jerbung (Penaeus merguiensis deMan, 1907) di Perairan Teluk Cendrawasih dan Sekitarnya, Papua. Jurnal Penelitian Perikanan Indonesia Vol 21 No. 3 Tahun 2015: 201 - 210. DOI http://dx.doi.org/10.15578/jppi.21.3.2015.201-210

Kusrini E. (2011). Menggali Sumberdaya Genetik Udang Jerbung (Fenneropenaeus meeguiensis De Man) sebagai Kandidat Udang Budaya Indonesia. Media Akuakultur Vol 6 No. 1 Tahun 2011:49-53 DOI http://dx.doi.org/10.15578/ma.6.1.2011.49. 53

Nufus, H. (2018). Konsentrasi Minyak Sawit Mentah (CPO) di Kawasan Pesisir Dumai Provinsi Riau. Jurnal Perikanan Terpadu. Vol 1 N. 1 Tahun 2015 : 99-106.

Nur A., Romadhona B., \& Widyany D.A. (2018). Produksi dan Performa Reproduksi Udang Jerbung (Penaeus merguiensis) Hasil Pembesaran di Tambak. Jrunal Perekayasan Akuakultur Indonesia Vol 1 No. 2 Tahun 2018:1-12

Nurdin, E \& Kembaren, D, D. (2015). Parameter Populasi Udang Putih (Penaeus merguiensis) di Perairan Sampit dan Sekitarnya, Kalimantan Tengah. Jurnal Bawal. Kementerian Kelautan Dan Perikanan Vol (7) 2 : 103-109. DOI http://dx.doi.org/10.15578/bawal.7.2.2015.103109
Mallawa, A., Musbir., Amri, F., \& Marimba, A. (2012). Analisis Struktur Ukuran Ikan Cakalang (Katsuwonus pelamis) Menurut Musim, Daerah dan Teknologi Penangkapan di Perairan Luwu Teluk Bone Sulawesi Selatan. Jurnal Balik Diwa Vol 3 No.2 Tahun 2012: 29 - 38.

Marini, M., Suman, A., Farajallah, A., \& Wardiatno, Y. (2017). Identifiying Penaes merguiensis de Man, 1888 stocks in Indonesian Fisheries Management Area 573:a truss network analysis approach. AACL Bioflux. Vol 10 No. 4 Tahun 2017. 922-935.

Marlian, N. (2017). Hubungan Parameter Kualitas Air Terhadap Kelimpahan Fitoplankton di Perairan Teluk Meulaboh Aceh Barat. Journal of Aceh Aquatic Science Vol 1 No 1 Tahun 2017:18-31.

Merian R.D., Mubarak., \& Sutikno S. (2017). Analisa Kualitas Perairan Muara Sungai Dumai ditinjau dari Aspek Fisika, Kima dan Biologi. Jurnal Dinamika Lingkungan Indonesia Vol 3 No. 2 Tahun 2016:107-112. DOI http://dx.doi.org/10.31258/dli.3.2.p.107-112

Melmambbessy, E. H. P. (2011). Ukuran Pertama Kali Matang Gonad Udang Penaeus merguiensis De Man (1988) di Laut Arafura pada Distrik Naukenjerai Kabupaten Merauke. Jurnal Agribisnis dan Perikanan Vol 4 No. 2 Tahun 2011:75-81. DOI https://doi.org/10.29239/j.agrikan.4.2.75-81

Purwaningsih, R., Widjaja, S., \& Partiwi S G. (2012). Pengembangan model simulasi kebijakan pengelolaan ikan berkelanjutan. Jurnal Teknik Industri Vol 14 No.1 Tahun 2012: 25-34. DOI http://dx.doi.org/10.9744/jti.14.1.25-34

Pane, A. R. P., \& Kembaren, D. (2015). "Parameter Biologi Udang Kelong (Penaeus merguiensis) Di Perairan Langsa, Aceh. Bunga Rampai. Status Pemanfaatan Sumber Daya Ikan Di Perairan Selat Malaka (WPP - NRI 571)." In Ref Graphika. Jakarta, 96-106.

Pane, A. R. P., \& Widiyastuti, H. (2017). Beberapa Aspek Biologi Udang Kelong (Penaeus merguiensis dan Penaeus indicus) di perairan Aceh Timur, Nanggore Aceh Darussalam. Prosiding Simposium Nasional Krustasea. Pusat Riset Perikanan. Badan Riset dan Sumber Daya Manusia dan WWF Indonesia. $117-124$

Pane, A. R. P., \& Hasanah, A. (2017). Dinamika Populasi Udang Jerbung (Ferropenaeus merguiensis de Man 1889 dan Ferropenaeus indicus H. Milne Edwards, 1879) di Perairan Bengkalis dan Sekitarnya, Riau. Prosiding Semnas Bappeda Propinsi Jawa Tengah 2017. 334 - 342.

Priatna, A., \& Wijopriono. (2011). Estimasi Stok Sumber Daya Ikan dengan Metode Hidroakustik di Perairan Kabupaten Bengkalis. Jurnal Penelitian Perikanan Indonesia. Vol 17 No. 1 Tahun 2011:110. http://dx.doi.org/10.15578/jppi.17.1.2011.110

Purba, N. P., \& Khan A. M. A. (2010). Karateristik Fisika Kimia Perairan Pantai Dumai pada Musim Peralihan. Jurnal Akuatika Vol 1 No. 1 Tahun 2010: 70-83. 
Purnomo, B. H. (2012). Peranan Perikanan Tangkap Berkelanjutan Untuk Menunjang Ketahanan Pangan di Indonesia. Seminar Nasional Kedaulatan Pangan dan Energi 2012. Fakultas Pertanian Universitas Trunojoyo Madura.

Saputra, S.W., Djuwito., \& Rutiyaningsih, A. (2013). Beberapa Aspek Biologi Udang Jerbung (Penaeus merguiensis) di Perairan Cilacap Jawa Tengah. Journal Management of Aquatic Resourses. Vol 2 No.3 Tahun 2013: 47 - 55.

Sari, I. T., Solihin, I., \& Sondita, M. F. A. (2010). Peran Pangkalan Pendaratan Ikan (PPI) Kota Dumai dalam Mendukung Aktivitas Penangkapan Ikan. Skripisi http://repository.ipb.ac.id/handle/123456789/627 30.

Sentosa, A. A., Hedianto, D. A., \& Suryandari, A. (2017). Kebiasaan Makanan dan Interaksi Trifik Komunitas Udang Penaeid di Perairan Aceh Timur. Bawal. Vol 9 No. 3 Tahun 2017:197-206. DOI http://dx.doi.org/10.15578/bawal.9.3.2017.197206

Silaen, S. N., \& Mulya M. B., (2018). Density and White Shrimp Growth Pattern (Penaeus merguiensis) in Kampung Nipah Waters of Perbaungan Sumatera Utara. IOP Confrence Series Earth and Envriomental Science. 130 Tahun 2018. DOI doi :10.1088/1755-1315/130/1/012044

Syahrial., Sustriani, Y., Susammesin, V. A., Taher, D. P., Atikah, N., Lubis, K.M., Illahi, I., Mulyadi, A., Amin, B., \& Siregar S.H., (2017). Regenerasi Alami Semai Rhizophora apiculate di Kawasan Industri Perminyakan dan Kawasan Non Industri Provinsi Riau. Jurnal Enggano Vol 2 No.2 Tahun 2017:208217.

Syahrial. (2018). Kondisi Stomata dan Morfologi Daun Rhizophora apiculate Pada Kawasan dan Non-Kawasan Industri Perminyakan di Provinsi Riau. Journal of Marine Research and Technology Vol 1:11-16. DOI https://doi.org/10.24843/JMRT.2018.v01.i01

Suman, A., \& Prisantoso, B. I. (2017). Karateristik Populasi Udang Jerbung (Penaeus merguiensis de Man, 1888) di perairan Cilacap dan Sekitarnya. Jurnal Penelitian Perikanan Indonesia. Vol 23 No. 1 Tahun 2017:11-18. DOI http://dx.doi.org/10.15578/jppi.23.1.2017.11-18

Suman, A., Hasanah, A., Ernawati, T., \& Pane, A. R. P. (2017). The population dynamic of banana prawn (Penaeus merguiensis de Man) in Tanah Laut Waters, South Kalimantan. Indonesiaan Fisheries Research Journal. Vol 23 No.1 Tahun 2017:17 22. DOI http://dx.doi.org/10.15578/ifrj.23.1.2017.17-22

Suman, A., Kembaren, D. D., Pane, A. R. P \& Taufik, M. (2020). Status Stok Udang Jerbung (Penaeus merguiensis) di Perairan Bengkalis dan sekitarnya serta Kemugkinan Pengelolaannya secara Berkelanjutan. Jurnal Kebijakan Perikanan Indonesia. Vol 12 No 1. Tahun 2020 : 11 - 22. DOI http://dx.doi.org/10.15578/jkpi.12.1.2020.11-22
Steel, R. D. G \& Torrie, J. H. (1993). Prinsip Dan Prosedur Stasitika Suatu Pendekatan Biometrik. Jakarta: PT Gramedia Pustaka Utama.

Syahminan., Riani, E., Anwar, S., \& Rifardi. (2015). Telaah Logam Berat $\mathrm{Pb}$ dan $\mathrm{Cd}$ pada Sedimen di Perairan Barat Laut Dumai-Riau. Jurnal Pengelolaan Sumberdaya Alam dan Lingkungan Vol 5 No.2 Tahun 2015:133-140. DOI http://dx.doi.org/10.29244/jps1.5.2.133

Tirtadanu., \& Ernawati, T. (2016). Kajian Biologi Udang Jerbung (Penaeus merguiensis De Man, 1888) di Perairan Utara Jawa Tengah. Jurnal Bawal. Kementerian Kelautan dan Perikanan. Vol 8 No. 2 Tahun 2016:109-118. DOI http://dx.doi.org/10.15578/bawal.8.2.2016.109116.

Tirtadanu., \& Panggabean, A. S. (2018). Catch rate and population parameters of banana prawn Penaeus merguiensis in Kaimana waters, West Papua, Indonesia. AACL Bioflux. Vol 11 No.4 Tahun 2018:1378-1387.

Tirtadanu., \& Chodrijah, U. (2020). Laju Tangkap, Karakteristik Biologi dan Status Pemanfaatan Udang Jerbung (Penaeus merguiensis De Mann, 1988) dan Udang Dogol (Metapenaeus affinis $H$. Milne Edwards, 1837) di Perairan Cilacap. Jurnal Penelitian Perikanan Indonesia. Vol 26 No.1 Tahun 2020: 47-58. DOI http://dx.doi.org/10.15578/jppi.26.1.2020.47-58 